\title{
REVIEW
}

\section{Lobular breast cancer: incidence and genetic and non-genetic risk factors}

\author{
Laure Dossus ${ }^{1,2}$ and Patrick R Benusiglio $3,4^{*}$
}

\begin{abstract}
While most invasive breast cancers consist of carcinomas of the ductal type, about 10\% are invasive lobular carcinomas. Invasive lobular and ductal carcinomas differ with respect to risk factors. Invasive lobular carcinoma is more strongly associated with exposure to female hormones, and therefore its incidence is more subject to variation. This is illustrated by US figures during the 1987 to 2004 period: after 12 years of increases, breast cancer incidence declined steadily from 1999 to 2004, reflecting among other causes the decreasing use of menopausal hormone therapy, and these variations were stronger for invasive lobular than for invasive ductal carcinoma. Similarly, invasive lobular carcinoma is more strongly associated with early menarche, late menopause and late age at first birth. As for genetic risk factors, four high-penetrance genes are tested in clinical practice when genetic susceptibility to breast cancer is suspected, BRCA1, BRCA2, TP53 and CDH1. Germline mutations in BRCA1 and TP53 are predominantly associated with invasive ductal carcinoma, while BRCA2 mutations are associated with both ductal and lobular cancers. $\mathrm{CDH1}$, the gene coding for the E-cadherin adhesion protein, is of special interest as mutations are associated with invasive lobular carcinoma, but never with ductal carcinoma. It was initially known as the main susceptibility gene for gastric cancer of the diffuse type, but the excess of breast cancers of the lobular type in CDH1 families led researchers to identify it also as a susceptibility gene for invasive lobular carcinoma. The risk of invasive lobular carcinoma is high in female mutation carriers, as about 50\% are expected to develop the disease. Carriers must therefore undergo intensive breast cancer screening, with, for example, yearly magnetic resonance imaging and mammogram starting at age 30 years.
\end{abstract}

\section{Introduction}

Invasive breast cancer is a heterogeneous disease of two main histological types, invasive ductal carcinoma (IDC) and invasive lobular carcinoma (ILC), IDC being by far the most common. IDC and ILC differ with respect to risk factors, and these differences are often overlooked as researchers and clinicians tend to treat breast cancer as a single, homogeneous entity, or only explore the potential differences between the two types in post hoc analyses. In this review, we focus on the specificities of ILC regarding incidence and risk factors. We show that ILC is more strongly associated with exposure to female hormones than IDC and that, as a result, its incidence in the past 25 to 30 years has varied more than that of

\footnotetext{
* Correspondence: pbenusiglio.wk@gmail.com

${ }^{3}$ Oncogénétique Clinique, Département de Médecine Oncologique, Gustave

Roussy Cancer Campus, 94805 Villejuif, France

${ }^{4}$ Centre Expert National Cancers Rares PREDIR, Hôpital Bicêtre AP-HP, 94275

Le Kremlin-Bicêtre, France

Full list of author information is available at the end of the article
}

IDC, depending on environmental and lifestyle factors such as menopausal hormone therapy (MHT). As for genetic risk factors, we show that ILC is often underrepresented in patients carrying mutations in the best-known breast cancer susceptibility genes (BRCA1, TP53), but that it is the only invasive histological type associated with $C D H 1$, the diffuse gastric cancer susceptibility gene.

\section{Incidence}

ILCs represent about $10 \%$ of invasive breast cancer cases $[1,2]$. Patients diagnosed with ILC are, on average, about 3 years older than those with IDC [3]. Compared with patients with IDC, ILCs are generally diagnosed at a more advanced stage, with larger tumor sizes and more frequent lymph node invasion, and are more often estrogen receptor- and progesterone receptor-positive [3]. Studies conducted in the US indicated a $65 \%$ increase in the incidence of ILC between 1987 and 1999, while IDC rates increased by only $3 \%$ during the same period [1]. However, 
after 1999, the age-adjusted incidence rates of both ILC and IDC steadily declined $[2,4]$.

More specifically, an average annual decrease of $4.6 \%$ for ILC was noted between 1999 and 2004 in 44 American states and the District of Columbia, with the largest drop in 2003 when an $8.5 \%$ decrease was observed. The average annual decrease for IDC was smaller, $3.3 \%$ for the same five-year period. It is likely that the decreasing use of MHT contributed to this decline, with an acceleration in use reduction from 2002 onwards associated with the publication of the Women's Health Initiative (WHI) trial results $[4,5]$.

\section{Environmental and lifestyle risk factors}

Most breast cancers are related to female hormones, and therefore any factor that increases exposure to these hormones is a potential risk factor. In particular, reproductive factors associated with increased exposure to endogenous estrogens produced by the ovaries, such as earlier menarche, late menopause, low parity, and late age at first birth, are recognized breast cancer risk factors [6-8]. Similarly, women exposed to exogenous hormones (for example, through MHT or oral contraceptives) are often at increased risk [5,9-12].

Lifestyle factors are also associated with breast cancer. There is an estimated $10 \%$ increase in risk per $10 \mathrm{~g}$ of ethanol consumed every day [13]. Being overweight or obese is also associated with breast cancer risk, but only in postmenopausal women, with a gain of $5 \mathrm{~kg} / \mathrm{m}^{2}$ in body mass index (BMI) resulting in an $8 \%$ increase in disease risk [13]. On the contrary, excess weight is associated with a decrease in risk in premenopausal women. Again, these associations can be explained by hormonal factors: alcohol consumption and postmenopausal obesity are related to higher circulating estrogen levels [14]. In postmenopause, elevated estrogen levels are most probably due to extraglandular production in the adipose tissue, whereas in premenopause, the decrease in female hormone synthesis associated with anovulatory cycles in obese women likely explains the inverse association with breast cancer [14].

ILC being more often hormone receptor-positive than IDC, one would expect hormone-related risk factors to be more strongly associated with lobular than ductal carcinoma.

\section{Menopausal hormone therapy}

MHT in the form of combined estrogen plus progestin treatment (combined hormone therapy or $\mathrm{CHT}$ ) most likely increases the risk of breast cancer, whereas the effects of estrogen-only treatments (estrogen hormone therapy or EHT) are less clear [12,15-17]. In 2002 the WHI trial demonstrated that $\mathrm{CHT}$ use increased breast cancer risk [5]. In this prospective, randomized primary prevention trial, there was a $26 \%$ increase in risk of invasive breast cancer in patients taking CHT. A subsequent, detailed analysis of tumor characteristics concluded that the percentages and distribution of IDC and ILC were similar in the CHT and the placebo group [18]. In the WHI estrogen-alone trial that included women with a prior hysterectomy, use of conjugated equine estrogens was associated with a 20 to $25 \%$ decreased risk of invasive breast cancer compared with the placebo group, a reduction in risk that was observed with IDC $(-30 \%)$ in subgroup analyses, but not with ILC, perhaps because of insufficient statistical power $[17,19]$. This reduction in risk is consistent with preclinical, cellular and animal models showing that low-dose estradiol can cause tumor regression and apoptosis after prior estrogen deprivation [19-21].

Twenty-five observational studies (15 case control and 10 cohort studies) have evaluated the association between MHT and breast cancer risk by histological types [22-46]. Although the heterogeneity between histological subgroups was not always formally tested or did not reach statistical significance, a vast majority of these studies showed that MHT was more strongly associated with ILC than IDC. As for the type of MHT, studies that reported associations separately for $\mathrm{CHT}$ and EHT are presented in Figure 1. For current CHT use, the relative risk (RR) was generally lower than 2.0 for IDC (overall RR 1.5, 95\% confidence interval (CI) 1.5 to 1.6 ) while it exceeded 2.0 for ILC in a majority of studies (overall RR 2.0, 95\% CI 1.9 to 2.1). RR associated with current EHT use varied between 0.7 and 2.0 for IDC (overall RR 1.1, 95\% CI 1.0 to 1.1) and between 1.0 and 2.1 for ILC (overall RR 1.4, 95\% CI 1.3 to 1.5). Intriguingly, studies that restricted their analyses to estrogen receptor and progesterone receptor tumors still showed a stronger association for ILC than for IDC, suggesting that mechanisms independent of the hormone receptors account for the increased sensitivity of ILC to MHT [36,38,40-42,45,46].

\section{Oral contraceptives}

Oral contraceptives are expected to become less of a risk factor as recent formulations contain less hormones than those available decades ago [12]. To our knowledge, there are no data indicating that oral contraceptives in general have a differential effect on breast cancer depending on the histological subtype.

\section{Reproductive factors}

A recent meta-analysis of individual participant data from 85 studies showed a significantly stronger association with age at menarche for ILC than for IDC (RR per year younger at menarche 1.073 and 1.035 , respectively, $P$ heterogeneity $=0.0001$ ) [7]. There was also significant 


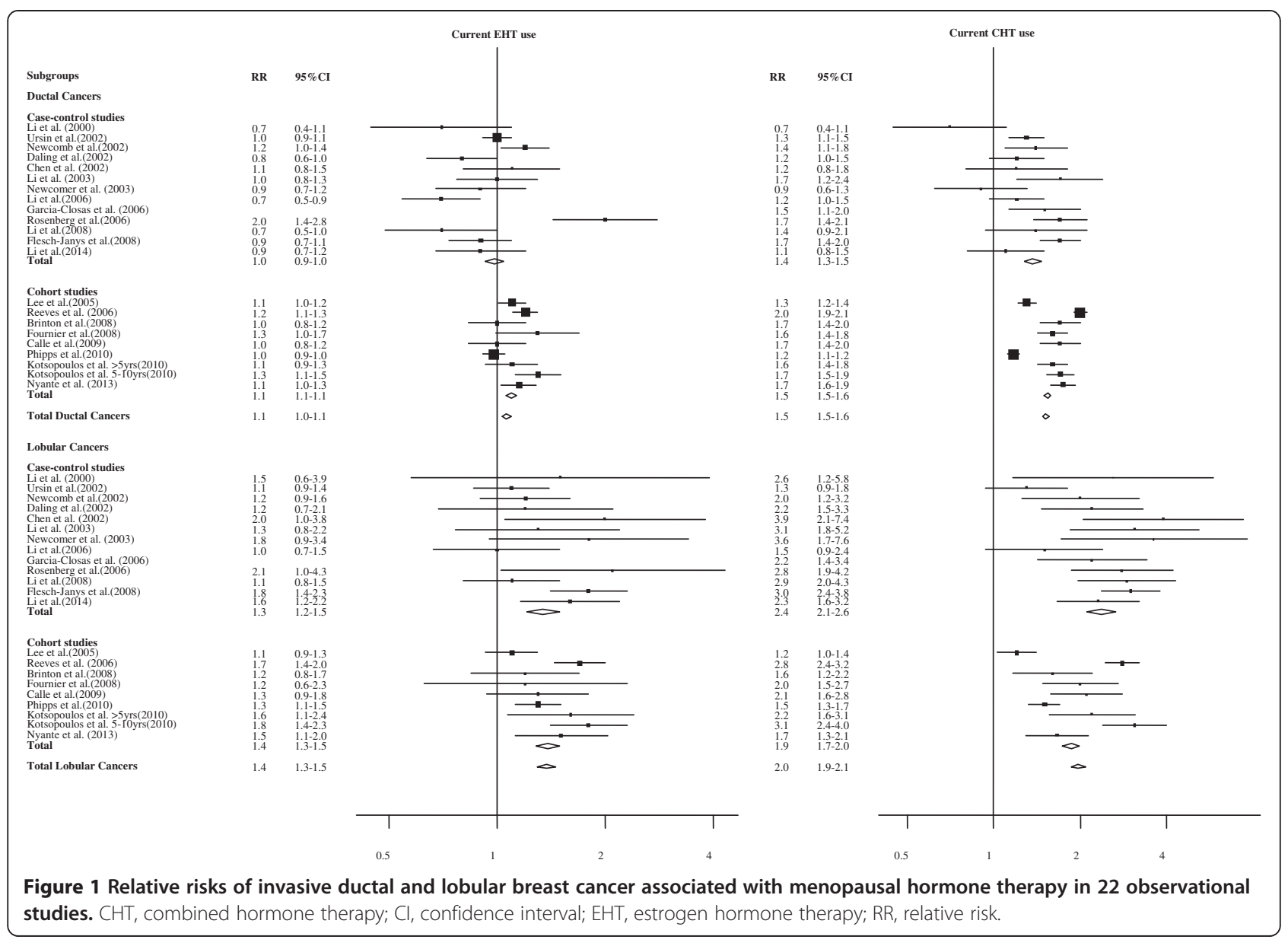

heterogeneity between ILC and IDC with respect to the association with age at menopause, with a $3.6 \%$ increase in risk of ILC per year older at menopause, versus $2.6 \%$ for IDC ( $P$ heterogeneity $=0.006)$.

Late age at first birth is associated with an increased risk of breast cancer [8]. Among the 19 studies that explored the association between breast cancer type and age at first birth [32,33,35,42-45,47-58], 14 observed higher risk estimates for ILC than for IDC [33,35,42-45,47,49,51,54-58]. Associations with other reproductive factors, such as parity and breastfeeding, were in general not markedly different between ILC and IDC, although a few studies reported stronger associations with parity for IDC than for ILC $[42,43,47,49,51]$.

\section{Alcohol}

Among eight studies (four case control and four cohort studies) that examined the association between alcohol consumption and breast cancer by histological subtype [33,35,42,45,59-62], two observed a significant heterogeneity between ILC and IDC [33,62]. RRs were higher for ILC than for IDC $[33,35,42,45,59,60,62]$.

\section{Other risk factors}

Four cohort studies $[42,43,45,63]$ and five case-control studies $[32,33,35,44,50]$ examined the associations between anthropometric measures (mostly BMI and height) and risk of breast cancer by histogical type. Overall, none observed significant heterogeneity between IDC and ILC regarding the association with BMI or height. The two studies that examined the association with physical activity did not observe significant heterogeneity between IDC and ILC $[45,64]$.

\section{Genetic risk factors}

Along with environment and lifestyle, a woman's genetic background contributes to her risk of having breast cancer. Her risk of developing breast cancer increases if she has a family history of the disease. In a re-analysis of 52 studies comparing cancer incidence in relatives of breast cancer cases and in controls, RR for breast cancer increased with increasing numbers of affected first-degree relatives: compared with women who had no affected relative, the RR was $1.80,2.93$, and 3.90 , respectively, for women with one, two, and three or more affected first-degree relatives [65]. RR was greatest at young ages and, for women of a given age, was greater the 
younger the relative was when diagnosed. Twin studies provide evidence that genes contribute substantially to this excess familial risk of breast cancer. Combined data on all twin pairs listed in three North-European registries showed that concordance for breast cancer was two times higher among monozygotic twins, who share all their genes, than among dizygotic twins, who share half their genes [66].

About 90 genes or genetic loci are involved in breast cancer susceptibility in general, through rare, moderate to high penetrance mutations (lifetime risk $>20 \%$ ), the penetrance being the risk for a mutation carrier of developing a disease, or through common variants associated with risks that are only slightly increased compared with the wild-type allele ( $R R=1$ to 1.5 ). Mutations and variants are germline; that is, they are part of the genetic identity of the individual. A comprehensive review of genetic susceptibility to breast cancer is beyond the scope of this article, as we are focusing here on the specificities of ILC. Numerous reviews have been written on the issue, and we invite those interested to read two recent and extremely well-written articles $[67,68]$.

Four high-penetrance genes are tested in clinical practice when genetic susceptibility to breast cancer is suspected: BRCA1, BRCA2, TP53 and CDH1. Germline mutations in $B R C A 1$ and TP53 are predominantly associated with IDC, $B R C A 2$ mutations are associated with both ductal and lobular tumors, while mutations in $C D H 1$ are exclusively associated with ILC. Mutations in PTEN and STK11 cause, respectively, Cowden and Peutz-Jaeger syndrome, and breast cancer risk is also high in affected females. However, the presenting manifestations are usually not related to breast cancer (for example, macrocephaly, central nervous system abnormalities, mucocutaneous lesions, gastrointestinal hamartomas) and we shall therefore not discuss these two syndromes further $[69,70]$.

\section{BRCA1, BRCA2 and TP53}

In the 1990s, linkage analyses and positional cloning in breast and breast-ovarian cancer families led to the identification of BRCA1 and BRCA2 [71,72]. Both have a role in maintaining DNA integrity. Mutations confer a high risk of breast and ovarian cancer with estimated breast cancer penetrances of $60 \%$ for $B R C A 1$ and $55 \%$ for $B R C A 2$ by age 70 years [73]. However, not all breast and breast-ovarian cancer families carry a mutation in BRCA1 or BRCA2 [74]. For example, $41 \%$ of families with four or five cases of breast cancer under the age of 60 years - but no ovarian cancer - are carriers, but that proportion increases to $88 \%$ in families with at least four breast cancer cases and one case of ovarian cancer. Mutations are rare in populationbased, unselected breast cancer cases. The detection rate was, for example, $2 \%$ in a large English series of women diagnosed below age 55 years, although it increased to $12 \%$ in the subset of women diagnosed before age 35 years [75]. These are likely underestimates, as the sensitivity of gene analysis techniques was lower in the late 1990s than it is today. Some phenotypic characteristics influence the probability of carrying a mutation in BRCA1 or BRCA2. For example, up to $15 \%$ of unselected women with triplenegative breast cancer have a $B R C A 1$ mutation, while there does not seem to be an association with BRCA2 [76]. Similarly, the distribution among different breast cancer types varies according to the predisposing gene involved. The CIMBA Consortium analyzed the pathology of invasive breast cancers in 6,893 BRCA1/2 mutation carriers, and found that only $2.2 \%$ of tumors associated with $B R C A 1$ were ILC. In contrast, the proportion of ILCs in BRCA2 mutation carriers was $8.4 \%$, closer to the characteristics of breast cancers from the general population $[1,77]$.

Li-Fraumeni syndrome is characterized by early onset of a variety of tumors. It is caused by mutations in the tumour-suppressor gene TP53. Affected individuals are at increased risk of sarcoma, premenopausal breast cancer, brain cancer, adrenocortical cancer, leukaemia, lymphoma, germ cell tumor, melanoma, lung cancer and cancer of the digestive tract [78]. Cancer risk by age 45 years is about $41 \%$ in males and $84 \%$ in females; lifetime risk is $73 \%$ in males, and approaches $100 \%$ in females [79]. The majority of cancers in females are breast cancers, and most breast cancers are diagnosed before age 45 years. Little is known regarding the histological characteristics of breast cancers associated with germline TP53 mutations, but the two studies that have examined the issue have only shown tumors of the ductal type - and none of the lobular type - out of a total of 48 cancers in mutation carriers [80,81]. These data suggest that TP53 might predispose exclusively to IDC, and not to ILC. Confirmatory studies are nevertheless needed, and it seems premature at this stage to exclude ILC from the tumor spectrum associated with $\mathrm{Li}$-Fraumeni syndrome.

ILCs are therefore very much underrepresented in carriers of BRCA1 and TP53 mutations, while their frequency in $B R C A 2$ mutation carriers is more similar to that in the general population. This overall underrepresentation of lobular cancers contrasts with observations made in over 40,000 Utah cases with genealogical records showing unusually high levels of familial clustering for ILC, and therefore a higher contribution of genetic, inherited factors compared with IDC [82]. The CDH1 susceptibility gene likely explains at least some of this excess in familial risk, the remainder being accounted for by genes and loci that are yet to be discovered.

\section{$\mathrm{CDH} 1$}

CDH1 is located on chromosome $16 \mathrm{q} 22$ and codes for the E-cadherin protein. E-cadherin maintains tissue integrity as it mediates cell-cell adhesion. There is also evidence that forced expression of the protein inhibits the 
growth of breast cancer cells via mechanisms that are yet to be determined, and that the protein therefore controls cell proliferation in addition to its anti-invasion properties $[83,84]$. Its tumor-suppression role is limited to breast cancer of the lobular type. Indeed, loss of expression is observed in the majority of lobular breast carcinomas, and, in the few tumors with conserved expression, E-cadherin integrity is impaired [85]. On the contrary, expression is unaffected in ductal breast carcinomas [86]. First-event somatic mutations, with subsequent loss of heterozygosity or promoter methylation, are classically responsible for $C D H 1$ inactivation following the two-hit loss-of-function model [84]. Therefore, an individual with an inherited, germline mutation in $C D H 1$ is at increased risk of ILC as a single somatic event is sufficient to generate tumorigenesis.

Readers should be reminded here that $C D H 1$ was initially known as a susceptibility gene for gastric cancer of the diffuse type, following the identification of germline mutations in Caucasian, Maori and African-American families with multiple affected individuals [87-91]. Like in ILC, E-cadherin inactivation is an early event in diffuse gastric cancer development and, as expected in this context, the histopathological characteristics of diffuse gastric cancer show similarities with ILC, with neoplastic cells permeating the mucosa and wall as scattered individual signet-ring cells or small clusters in an infiltrative growth pattern $[87,92,93]$. In a collaborative study based on 11 CDH1 families, the International Gastric Cancer Linkage Consortium showed that the clinical penetrance for diffuse gastric cancer was high, as the estimated risk for carriers of developing the disease was 67 to $83 \%$ [94]. Interestingly, that same study observed that, in addition to diffuse gastric cancer, female carriers were also at high risk of ILC [94]. Indeed, there were seven cases of breast cancers in these $11 \mathrm{CDH1}$ families, some of them at an early age, and histology, when documented, was systematically of the lobular type. The estimated risk for ILC was 39\% by age 80 years. Subsequent studies of families with $C D H 1$ mutations led to similar conclusions: in four families with a total of 22 breast cancers, all invasive tumors for which a pathological report was available were lobular $[95,96]$. As for penetrance, a recent estimate derived from 67 mutation-positive families is 56\% (P Kaurah and D Huntsman, personal communication).

There is increasing evidence that a personal history of early-onset bilateral ILC or family history of multiple ILC at a young age, in the absence of diffuse gastric cancer in the family, can be associated with $C D H 1$ germline mutations. Masciari and colleagues [97] described the case of a woman carrier with unilateral ILC at age 42 years, and whose mother had been diagnosed with the same condition at age 28 years. We reported three female cases who presented with bilateral ILC below age 50 years and turned out to carry mutations in $C D H 1$ [98]. In the only systematic study of women with bilateral lobular breast neoplasia before age 60 years (ILC and/or lobular carcinoma in situ), Petridis and colleagues [99] found mutations in 4 out of $50(8 \%)$ women. Schrader and colleagues [100] had previously looked into the issue with discrepant findings, as they only found mutations or potentially causal variants in 4 out of 318 (1\%) women with ILC either before age 45 years or regardless of age if there was a family history of breast cancer. However, it was not known how many women actually had a family history of breast cancer of the lobular type, as histology in relatives was not specified. Furthermore, there was no upper age limit for women with familial ILC, and BRCA1/2 mutations had not been excluded in all cases. Cancer geneticists should therefore consider prescribing $C D H 1$ germline analysis in patients with a personal or family history of multiple pathologically proven early-onset ILC, but no diffuse gastric cancer, as the identification of a mutation would have direct and dramatic clinical implications. The patient would be offered riskreducing gastrectomy (assuming her ILC has been successfully treated), given the high risk of diffuse gastric cancer $[94,101]$. Her adult relatives would then undergo targeted genetic analysis to see if they carry the mutation, and those who do would also be offered risk-reducing gastrectomy. Surveillance with upper endoscopy is a poor alternative to prophylactic surgery, except in very specific situations (for example, young athletes wishing to delay surgery for professional reasons, and elderly or frail patients), as this screening modality frequently misses foci of diffuse carcinoma in mutation carriers even when accompanied by multiple random biopsies [102,103]. Large, multicenter studies on the prevalence of $C D H 1$ mutations in patients and families with multiple cases of ILC are needed.

The high risk of ILC in females carrying a CDH1 mutation justifies personalized, intensive surveillance. The consensus $2010 \mathrm{CDH1}$ paper recommended that breast cancer surveillance be carried out within specific research protocols, and suggested annual magnetic resonance imaging (MRI) and mammogram starting at age 35 years [101]. As ILC risk is close to the overall breast cancer risk seen in carriers of BRCA1/BRCA2 mutations, it seems reasonable to offer the same type of surveillance as a routine procedure, and start screening at age 30 years with annual MRI and mammogram [104,105]. Risk-reducing mastectomy could be an alternative. Updated international recommendations on the management of $C D H 1$ mutation carriers that will address the issue are expected soon.

\section{Other genes and future perspectives}

Over 80 other breast cancer susceptibility genes and loci have been identified in the past few years, but again none have entered clinical practice either because of the difficulty in interpreting results from sequencing analyses 
or because the RR associated with the mutated alleles is so low that there is at best limited clinical relevance $[67,106]$. Only one low-penetrance variant was specifically associated with ILC in a pooled, post hoc analysis of 36 case-control studies [106].

\section{Conclusion}

We have reviewed in this article the specificities of ILC regarding disease incidence and environmental, lifestyle and genetic risk factors, and have shown that there were notable differences with IDC. ILC is more strongly related to endogenous and exogenous female hormones and its incidence, therefore, is more subject to variation, depending, for example, on key reproductive factors such as age at menarche or at first pregnancy, or on MHT use. Genetic risk factors vary depending on breast cancer histology, and $\mathrm{CDH} 1$ proves that genes involved in susceptibility to ILC do not have to be involved in IDC susceptibility. The typespecific hypothesis is hardly ever explored in breast cancer epidemiology. It is essential, therefore, that, in the near future, studies start turning their attention specifically to ILC instead of relying on post hoc exploratory analyses, or on data extracted from families with mutations predisposing primarily to other cancers. More epidemiological studies are still needed to establish whether associations with other known (physical activity, measures of anthropometry) or still unidentified risk factors differ depending on the histological type. As for genetic studies, large-scale projects focusing on women with unexplained early-onset or familial ILC are urgently needed, as there are certainly many more clinically relevant susceptibility genes to discover. The identification of specific risk factors would help define high-risk groups that could benefit from adapted, personalized screening strategies.

Note: This article is part of a series on Lobular breast cancer, edited by Ulrich Lehmann. Other articles in this series can be found at http://breast-cancer-research.com/series/LBC

\begin{abstract}
Abbreviations
BMI: Body mass index; CHT: Combined hormone therapy; Cl: Confidence interval; EHT: Estrogen hormone therapy; IDC: Invasive ductal carcinoma; ILC: Invasive lobular carcinoma; MHT: Menopausal hormone therapy; MRI: Magnetic resonance imaging; RR: Relative risk; WHI: Women's Health Initiative.
\end{abstract}

\section{Competing interests}

The authors declare that they have no competing interests.

\footnotetext{
Author details

${ }^{1}$ Inserm, Centre for research in Epidemiology and Population Health (CESP), U1018, Nutrition, Hormones and Women's Health team, 94805 Villejuif, France. ${ }^{2}$ Université Paris Sud, UMRS 1018, 94805 Villejuif, France. ${ }^{3}$ Oncogénétique Clinique, Département de Médecine Oncologique, Gustave Roussy Cancer Campus, 94805 Villejuif, France. ${ }^{4}$ Centre Expert National Cancers Rares PREDIR, Hôpital Bicêtre AP-HP, 94275 Le Kremlin-Bicêtre, France.
}

Received: 10 July 2014 Accepted: 3 March 2015

Published online: 13 March 2015

\section{References}

1. $\mathrm{Li} \mathrm{Cl}$, Anderson BO, Daling JR, Moe RE. Trends in incidence rates of invasive lobular and ductal breast carcinoma. JAMA. 2003;289:1421-4.

2. $\mathrm{Li} \mathrm{Cl}$, Daling JR. Changes in breast cancer incidence rates in the United States by histologic subtype and race/ethnicity, 1995 to 2004. Cancer Epidemiol Biomarkers Prev. 2007;16:2773-80.

3. Li Cl, Uribe DJ, Daling JR. Clinical characteristics of different histologic types of breast cancer. Br J Cancer. 2005;93:1046-52.

4. Eheman CR, Shaw KM, Ryerson AB, Miller JW, Ajani UA, White MC. The changing incidence of in situ and invasive ductal and lobular breast carcinomas: United States, 1999-2004. Cancer Epidemiol Biomarkers Prev. 2009:18:1763-9.

5. Rossouw JE, Anderson GL, Prentice RL, LaCroix AZ, Kooperberg C, Stefanick $M L$, et al. Risks and benefits of estrogen plus progestin in healthy postmenopausal women: principal results from the Women's Health Initiative randomized controlled trial. JAMA. 2002;288:321-33.

6. Collaborative Group on Hormonal Factors in Breast Cancer. Breast cancer and breastfeeding: collaborative reanalysis of individual data from 47 epidemiological studies in 30 countries, including 50302 women with breast cancer and 96973 women without the disease. Lancet. 2002;360:187-95.

7. Collaborative Group on Hormonal Factors in Breast Cancer. Menarche, menopause, and breast cancer risk: individual participant meta-analysis, including 118964 women with breast cancer from 117 epidemiological studies. Lancet Oncol. 2012;13:1141-51.

8. Clavel-Chapelon F, Gerber M. Reproductive factors and breast cancer risk. Do they differ according to age at diagnosis? Breast Cancer Res Treat. 2002;72:107-15.

9. Collaborative Group on Hormonal Factors in Breast Cancer. Breast cancer and hormonal contraceptives: collaborative reanalysis of individual data on 53297 women with breast cancer and 100239 women without breast cancer from 54 epidemiological studies. Lancet. 1996;347:1713-27.

10. Collaborative Group on Hormonal Factors in Breast Cancer. Breast cancer and hormone replacement therapy: collaborative reanalysis of data from 51 epidemiological studies of 52,705 women with breast cancer and 108,411 women without breast cancer. Lancet. 1997;350:1047-59.

11. Zhu H, Lei X, Feng J, Wang Y. Oral contraceptive use and risk of breast cancer: a meta-analysis of prospective cohort studies. Eur J Contracept Reprod Health Care. 2012;17:402-14.

12. Hilakivi-Clarke L, de Assis S, Warri A. Exposures to synthetic estrogens at different times during the life, and their effect on breast cancer risk. J Mammary Gland Biol Neoplasia. 2013;18:25-42.

13. World Cancer Research Fund/American Institute for Cancer Research. Food, nutrition, physical activity, and the prevention of cancer: a global perspective. Washington DC: AICR; 2007. http://www.wcrf.org/int/researchwe-fund/continuous-update-project-cup/second-expert-report.

14. Travis RC, Key TJ. Oestrogen exposure and breast cancer risk. Breast Cancer Res. 2003:5:239-47.

15. Colditz GA. Estrogen, estrogen plus progestin therapy, and risk of breast cancer. Clin Cancer Res. 2005;11:909s-17s.

16. Fournier A, Berrino F, Clavel-Chapelon F. Unequal risks for breast cancer associated with different hormone replacement therapies: results from the E3N cohort study. Breast Cancer Res Treat. 2008;107:103-11.

17. Stefanick ML, Anderson GL, Margolis KL, Hendrix SL, Rodabough RJ, Paskett $E D$, et al. Effects of conjugated equine estrogens on breast cancer and mammography screening in postmenopausal women with hysterectomy. JAMA. 2006;295:1647-57.

18. Chlebowski RT, Hendrix SL, Langer RD, Stefanick ML, Gass M, Lane D, et al. Influence of estrogen plus progestin on breast cancer and mammography in healthy postmenopausal women: the Women's Health Initiative Randomized Trial. JAMA. 2003;289:3243-53.

19. Anderson GL, Chlebowski RT, Aragaki AK, Kuller LH, Manson JE, Gass M, et al. Conjugated equine oestrogen and breast cancer incidence and mortality in postmenopausal women with hysterectomy: extended follow-up of the Women's Health Initiative randomised placebo-controlled trial. Lancet Oncol. 2012;13:476-86.

20. Jordan VC. The 38th David A. Karnofsky lecture: the paradoxical actions of estrogen in breast cancer - survival or death? J Clin Oncol. 2008;26:3073-82. 
21. Lewis-Wambi JS, Jordan VC. Estrogen regulation of apoptosis: how can one hormone stimulate and inhibit? Breast Cancer Res. 2009;11:206.

22. Li Cl, Weiss NS, Stanford JL, Daling JR. Hormone replacement therapy in relation to risk of lobular and ductal breast carcinoma in middle-aged women. Cancer. 2000:88:2570-7.

23. Manjer J, Malina J, Berglund G, Bondeson L, Garne JP, Janzon L. Increased incidence of small and well-differentiated breast tumours in post-menopausal women following hormone-replacement therapy. Int J Cancer. 2001;92:919-22.

24. Chen CL, Weiss NS, Newcomb P, Barlow W, White E. Hormone replacement therapy in relation to breast cancer. JAMA. 2002;287:734-41.

25. Daling JR, Malone KE, Doody DR, Voigt LF, Bernstein L, Coates RJ, et al. Relation of regimens of combined hormone replacement therapy to lobular, ductal, and other histologic types of breast carcinoma. Cancer 2002;95:2455-64

26. Newcomb PA, Titus-Ernstoff L, Egan KM, Trentham-Dietz A, Baron JA, Storer BE, et al. Postmenopausal estrogen and progestin use in relation to breast cancer risk. Cancer Epidemiol Biomarkers Prev. 2002;11:593-600.

27. Ursin G, Tseng CC, Paganini-Hill A, Enger S, Wan PC, Formenti S, et al. Does menopausal hormone replacement therapy interact with known factors to increase risk of breast cancer? J Clin Oncol. 2002;20:699-706.

28. Newcomer LM, Newcomb PA, Potter JD, Yasui Y, Trentham-Dietz A, Storer $\mathrm{BE}$, et al. Postmenopausal hormone therapy and risk of breast cancer by histologic type (United States). Cancer Causes Control. 2003;14:225-33.

29. Li Cl, Malone KE, Porter PL, Weiss NS, Tang MT, Cushing-Haugen KL, et al. Relationship between long durations and different regimens of hormone therapy and risk of breast cancer. JAMA. 2003;289:3254-263.

30. Tjonneland A, Christensen J, Thomsen BL, Olsen A, Overvad K, Ewertz M, et al. Hormone replacement therapy in relation to breast carcinoma incidence rate ratios: a prospective Danish cohort study. Cancer. 2004;100:2328-37.

31. Lee S, Kolonel L, Wilkens L, Wan P, Henderson B, Pike M. Postmenopausal hormone therapy and breast cancer risk: the Multiethnic Cohort. Int J Cancer. 2006;118:1285-91.

32. Garcia-Closas M, Brinton LA, Lissowska J, Chatterjee N, Peplonska B, Anderson WF, et al. Established breast cancer risk factors by clinically important tumour characteristics. Br J Cancer. 2006;95:123-9.

33. Li Cl, Daling JR, Malone KE, Bernstein L, Marchbanks PA, Liff JM, et al. Relationship between established breast cancer risk factors and risk of seven different histologic types of invasive breast cancer. Cancer Epidemiol Biomarkers Prev. 2006;15:946-54.

34. Reeves GK, Beral V, Green J, Gathani T, Bull D. Hormonal therapy for menopause and breast-cancer risk by histological type: a cohort study and meta-analysis. Lancet Oncol. 2006;7:910-8.

35. Rosenberg LU, Magnusson C, Lindstrom E, Wedren S, Hall P, Dickman PW. Menopausal hormone therapy and other breast cancer risk factors in relation to the risk of different histological subtypes of breast cancer: a case-control study. Breast Cancer Res. 2006;8:R11.

36. Brinton LA, Richesson D, Leitzmann MF, Gierach GL, Schatzkin A, Mouw T, et al. Menopausal hormone therapy and breast cancer risk in the NIH-AARP Diet and Health Study Cohort. Cancer Epidemiol Biomarkers Prev. 2008;17:3150-60

37. Flesch-Janys D, Slanger T, Mutschelknauss E, Kropp S, Obi N, Vettorazzi E, et al. Risk of different histological types of postmenopausal breast cancer by type and regimen of menopausal hormone therapy. Int J Cancer. 2008;123:933-41.

38. Fournier A, Fabre A, Mesrine S, Boutron-Ruault MC, Berrino F, Clavel-Chapelon F. Use of different postmenopausal hormone therapies and risk of histologyand hormone receptor-defined invasive breast cancer. J Clin Oncol. 2008:26:1260-8.

39. $\mathrm{Li} \mathrm{Cl}$, Malone $\mathrm{KE}$, Porter $\mathrm{PL}$, Lawton TJ, Voigt LF, Cushing-Haugen $\mathrm{KL}$, et al. Relationship between menopausal hormone therapy and risk of ductal, lobular, and ductal-lobular breast carcinomas. Cancer Epidemiol Biomarkers Prev. 2008;17:43-50.

40. Calle EE, Feigelson HS, Hildebrand JS, Teras LR, Thun MJ, Rodriguez C. Postmenopausal hormone use and breast cancer associations differ by hormone regimen and histologic subtype. Cancer. 2009;115:936-45.

41. Slanger TE, Chang-Claude JC, Obi N, Kropp S, Berger J, Vettorazzi E, et al. Menopausal hormone therapy and risk of clinical breast cancer subtypes. Cancer Epidemiol Biomarkers Prev. 2009;18:1188-96.

42. Kotsopoulos J, Chen WY, Gates MA, Tworoger SS, Hankinson SE, Rosner BA Risk factors for ductal and lobular breast cancer: results from the nurses' health study. Breast Cancer Res. 2010;12:R106.
43. Phipps Al, Li Cl, Kerlikowske K, Barlow WE, Buist DS. Risk factors for ductal, lobular, and mixed ductal-lobular breast cancer in a screening population. Cancer Epidemiol Biomarkers Prev. 2010;19:1643-54.

44. Work ME, Andrulis IL, John EM, Hopper JL, Liao Y, Zhang FF, et al. Risk factors for uncommon histologic subtypes of breast cancer using centralized pathology review in the Breast Cancer Family Registry. Breast Cancer Res Treat. 2012;134:1209-20.

45. Nyante SJ, Dallal CM, Gierach GL, Park Y, Hollenbeck AR, Brinton LA. Risk factors for specific histopathological types of postmenopausal breast cancer in the NIH-AARP Diet and Health Study. Am J Epidemiol. 2013;178:359-71.

46. Li Cl, Daling JR, Haugen KL, Tang MT, Porter PL, Malone KE. Use of menopausal hormone therapy and risk of ductal and lobular breast cancer among women 55-74 years of age. Breast Cancer Res Treat. 2014;145:481-9.

47. LiVolsi VA, Kelsey JL, Fischer DB, Holford TR, Mostow ED, Goldenberg IS. Effect of age at first childbirth on risk of developing specific histologic subtype of breast cancer. Cancer. 1982;49:1937-40.

48. Ewertz M, Duffy SW. Risk of breast cancer in relation to reproductive factors in Denmark. Br J Cancer. 1988;58:99-104.

49. Wohlfahrt J, Mouridsen $\mathrm{H}$, Andersen PK, Melbye M. Reproductive risk factors for breast cancer by receptor status, histology, laterality and location. Int J Cancer. 1999;81:49-55

50. Li Cl, Malone KE, Porter PL, Weiss NS, Tang MT, Daling JR. Reproductive and anthropometric factors in relation to the risk of lobular and ductal breast carcinoma among women 65-79 years of age. Int J Cancer. 2003;107:647-51.

51. Ursin G, Bernstein L, Lord SJ, Karim R, Deapen D, Press MF, et al. Reproductive factors and subtypes of breast cancer defined by hormone receptor and histology. Br J Cancer. 2005;93:364-71.

52. $\mathrm{Li} \mathrm{Cl}$, Littman AJ, White E. Relationship between age maximum height is attained, age at menarche, and age at first full-term birth and breast cancer risk. Cancer Epidemiol Biomarkers Prev. 2007;16:2144-9.

53. Beaber EF, Holt VL, Malone KE, Porter PL, Daling JR, Li Cl. Reproductive factors, age at maximum height, and risk of three histologic types of breast cancer. Cancer Epidemiol Biomarkers Prev. 2008;17:3427-34.

54. Granstrom C, Sundquist J, Hemminki K. Population attributable risks for breast cancer in Swedish women by morphological type. Breast Cancer Res Treat. 2008;111:559-68.

55. Li Cl, Malone KE, Daling JR, Potter JD, Bernstein L, Marchbanks PA, et al. Timing of menarche and first full-term birth in relation to breast cancer risk. Am J Epidemiol. 2008;167:230-9.

56. Butt S, Borgquist S, Anagnostaki L, Landberg G, Manjer J. Parity and age at first childbirth in relation to the risk of different breast cancer subgroups. Int J Cancer. 2009;125:1926-34

57. Reeves GK, Pirie K, Green J, Bull D, Beral V. Reproductive factors and specific histological types of breast cancer: prospective study and meta-analysis. Br J Cancer. 2009;100:538-44.

58. Newcomb PA, Trentham-Dietz A, Hampton JM, Egan KM, Titus-Ernstoff L, Warren AS, et al. Late age at first full term birth is strongly associated with lobular breast cancer. Cancer. 2011;117:1946-56.

59. Nasca PC, Liu S, Baptiste MS, Kwon CS, Jacobson H, Metzger BB. Alcohol consumption and breast cancer: estrogen receptor status and histology. Am J Epidemiol. 1994;140:980-8.

60. Li Cl, Malone KE, Porter PL, Weiss NS, Tang MT, Daling JR. The relationship between alcohol use and risk of breast cancer by histology and hormone receptor status among women 65-79 years of age. Cancer Epidemiol Biomarkers Prev. 2003;12:1061-6.

61. Lew JQ, Freedman ND, Leitzmann MF, Brinton LA, Hoover RN, Hollenbeck $A R$, et al. Alcohol and risk of breast cancer by histologic type and hormone receptor status in postmenopausal women: the NIH-AARP Diet and Health Study. Am J Epidemiol. 2009;170:308-17.

62. Li Cl, Chlebowski RT, Freiberg M, Johnson KC, Kuller L, Lane D, et al. Alcohol consumption and risk of postmenopausal breast cancer by subtype: the women's health initiative observational study. J Natl Cancer Inst. 2010;102:1422-31.

63. Feigelson HS, Patel AV, Teras LR, Gansler T, Thun MJ, Calle EE. Adult weight gain and histopathologic characteristics of breast cancer among postmenopausal women. Cancer. 2006;107:12-21.

64. Schmidt ME, Steindorf K, Mutschelknauss E, Slanger T, Kropp S, Obi N, et al. Physical activity and postmenopausal breast cancer: effect modification by breast cancer subtypes and effective periods in life. Cancer Epidemiol Biomarkers Prev. 2008;17:3402-10. 
65. Collaborative Group on Hormonal Factors in Breast Cancer. Familial breast cancer: collaborative reanalysis of individual data from 52 epidemiological studies including 58,209 women with breast cancer and 101,986 women without the disease. Lancet. 2001;358:1389-99.

66. Lichtenstein P, Holm NV, Verkasalo PK, Iliadou A, Kaprio J, Koskenvuo M, et al. Environmental and heritable factors in the causation of cancer - analyses of cohorts of twins from Sweden, Denmark, and Finland. N Engl J Med. 2000;343:78-85.

67. Couch FJ, Nathanson KL, Offit K. Two decades after BRCA: setting paradigms in personalized cancer care and prevention. Science. 2014;343:1466-70.

68. Lalloo F, Evans DG. Familial breast cancer. Clin Genet. 2012;82:105-14.

69. Tan MH, Mester JL, Ngeow J, Rybicki LA, Orloff MS, Eng C. Lifetime cancer risks in individuals with germline PTEN mutations. Clin Cancer Res. 2012;18:400-7.

70. van Lier MG, Wagner A, Mathus-Vliegen EM, Kuipers EJ, Steyerberg EW, van Leerdam ME. High cancer risk in Peutz-Jeghers syndrome: a systematic review and surveillance recommendations. Am J Gastroenterol. 2010;105:1258-64

71. Miki Y, Swensen J, Shattuck-Eidens D, Futreal PA, Harshman K, Tavtigian S, et al. A strong candidate for the breast and ovarian cancer susceptibility gene BRCA1. Science. 1994;266:66-71.

72. Wooster R, Bignell G, Lancaster J, Swift S, Seal S, Mangion J, et al. Identification of the breast cancer susceptibility gene BRCA2. Nature. 1995;378:789-92

73. Mavaddat N, Peock S, Frost D, Ellis S, Platte R, Fineberg E, et al. Cancer risks for BRCA1 and BRCA2 mutation carriers: results from prospective analysis of EMBRACE. J Natl Cancer Inst. 2013;105:812-22.

74. Ford D, Easton DF, Stratton M, Narod S, Goldgar D, Devilee P, et al. Genetic heterogeneity and penetrance analysis of the BRCA1 and BRCA2 genes in breast cancer families. Am J Hum Genet. 1998;62:676-89.

75. Anglian Breast Cancer Study Group. Prevalence and penetrance of BRCA1 and BRCA2 mutations in a population-based series of breast cancer cases. Br J Cancer. 2000;83:1301-08.

76. Gonzalez-Angulo AM, Timms KM, Liu S, Chen H, Litton JK, Potter J, et al. Incidence and outcome of BRCA mutations in unselected patients with triple receptor-negative breast cancer. Clin Cancer Res. 2011;17:1082-9.

77. Mavaddat N, Barrowdale D, Andrulis IL, Domchek SM, Eccles D, Nevanlinna $\mathrm{H}$, et al. Pathology of breast and ovarian cancers among BRCA1 and BRCA2 mutation carriers: results from the Consortium of Investigators of Modifiers of BRCA1/2 (CIMBA). Cancer Epidemiol Biomarkers Prev. 2012;21:134-47.

78. Kamihara J, Rana HQ, Garber JE. Germline TP53 mutations and the changing landscape of Li-Fraumeni syndrome. Hum Mutat. 2014;35:654-62.

79. Chompret A, Brugieres L, Ronsin M, Gardes M, Dessarps-Freichey F, Abel A, et al. P53 germline mutations in childhood cancers and cancer risk for carrier individuals. Br J Cancer. 2000;82:1932-7.

80. Masciari S, Dillon DA, Rath M, Robson M, Weitzel JN, Balmana J, et al. Breast cancer phenotype in women with TP53 germline mutations: a Li-Fraumeni syndrome consortium effort. Breast Cancer Res Treat. 2012;133:1125-30.

81. Evans DG, Moran A, Hartley R, Dawson J, Bulman B, Knox F, et al. Long-term outcomes of breast cancer in women aged 30 years or younger, based on family history, pathology and BRCA1/BRCA2/TP53 status. Br J Cancer. 2010;102:1091-8

82. Cannon-Albright LA, Thomas A, Goldgar DE, Gholami K, Rowe K, Jacobsen M, et al. Familiality of cancer in Utah. Cancer Res. 1994;54:2378-85.

83. Cavallaro U, Dejana E. Adhesion molecule signalling: not always a sticky business. Nat Rev Mol Cell Biol. 2011;12:189-97.

84. Berx G, Van RF. The E-cadherin/catenin complex: an important gatekeeper in breast cancer tumorigenesis and malignant progression. Breast Cancer Res. 2001;3:289-93.

85. Rakha EA, Patel A, Powe DG, Benhasouna A, Green AR, Lambros MB, et al. Clinical and biological significance of E-cadherin protein expression in invasive lobular carcinoma of the breast. Am J Surg Pathol. 2010;34:1472-9.

86. Rakha EA, Teoh TK, Lee AH, Nolan CC, Ellis IO, Green AR. Further evidence that E-cadherin is not a tumour suppressor gene in invasive ductal carcinoma of the breast: an immunohistochemical study. Histopathology. 2013;62:695-701.

87. Guilford P, Hopkins J, Harraway J, McLeod M, McLeod N, Harawira P, et al. E-cadherin germline mutations in familial gastric cancer. Nature. 1998;392:402-5.

88. Gayther SA, Gorringe KL, Ramus SJ, Huntsman D, Roviello F, Grehan N, et al. Identification of germ-line E-cadherin mutations in gastric cancer families of European origin. Cancer Res. 1998;58:4086-9.
89. Guilford PJ, Hopkins JB, Grady WM, Markowitz SD, Willis J, Lynch H, et al. E-cadherin germline mutations define an inherited cancer syndrome dominated by diffuse gastric cancer. Hum Mutat. 1999;14:249-55.

90. Keller G, Vogelsang H, Becker I, Hutter J, Ott K, Candidus S, et al. Diffuse type gastric and lobular breast carcinoma in a familial gastric cancer patient with an E-cadherin germline mutation. Am J Pathol. 1999;155:337-42.

91. Richards FM, McKee SA, Rajpar MH, Cole TR, Evans DG, Jankowski JA, et al. Germline E-cadherin gene $(\mathrm{CDH} 1)$ mutations predispose to familial gastric cancer and colorectal cancer. Hum Mol Genet. 1999;8:607-10.

92. Becker KF, Atkinson MJ, Reich U, Becker I, Nekarda H, Siewert JR, et al. E-cadherin gene mutations provide clues to diffuse type gastric carcinomas. Cancer Res. 1994;54:3845-52.

93. Kumar V, Abbas AK, Fausto N, Mitchell RN. Pathology of the oral cavity and the gastrointestinal tract. In: Kumar V, Abbas AK, Fausto N, editors. Robbins basic pathology. 8th ed. Philadelphia: Saunders/Elsiever; 2007. p. 598-9.

94. Pharoah PD, Guilford P, Caldas C. Incidence of gastric cancer and breast cancer in $\mathrm{CDH} 1$ (E-cadherin) mutation carriers from hereditary diffuse gastric cancer families. Gastroenterology. 2001;121:1348-53.

95. Kaurah P, MacMillan A, Boyd N, Senz J, De LA, Chun N, et al. Founder and recurrent $\mathrm{CDH} 1$ mutations in families with hereditary diffuse gastric cancer. JAMA. 2007;297:2360-72.

96. Suriano G, Yew S, Ferreira P, Senz J, Kaurah P, Ford JM, et al. Characterization of a recurrent germ line mutation of the E-cadherin gene: implications for genetic testing and clinical management. Clin Cancer Res. 2005;11:5401-9.

97. Masciari S, Larsson N, Senz J, Boyd N, Kaurah P, Kandel MJ, et al. Germline E-cadherin mutations in familial lobular breast cancer. J Med Genet. 2007:44:726-31.

98. Benusiglio PR, Malka D, Rouleau E, De PA, Buecher B, Nogues C, et al. CDH germline mutations and the hereditary diffuse gastric and lobular breast cancer syndrome: a multicentre study. J Med Genet. 2013;50:486-9.

99. Petridis C, Shinomiya I, Kohut K, Gorman P, Caneppele M, Shah V, et al. Germline $\mathrm{CDH} 1$ mutations in bilateral lobular carcinoma in situ. $\mathrm{Br} J$ Cancer. 2014;110:1053-7.

100. Schrader KA, Masciari S, Boyd N, Salamanca C, Senz J, Saunders DN, et al. Germline mutations in $\mathrm{CDH} 1$ are infrequent in women with early-onset or familial lobular breast cancers. J Med Genet. 2011;48:64-8.

101. Fitzgerald RC, Hardwick R, Huntsman D, Carneiro F, Guilford P, Blair V, et al. Hereditary diffuse gastric cancer: updated consensus guidelines for clinical management and directions for future research. J Med Genet. 2010;47:436-44.

102. Hebbard PC, MacMillan A, Huntsman D, Kaurah P, Carneiro F, Wen X, et al. Prophylactic total gastrectomy (PTG) for hereditary diffuse gastric cancer (HDGC): the Newfoundland experience with 23 patients. Ann Surg Oncol. 2009;16:1890-5

103. Fujita H, Lennerz JK, Chung DC, Patel D, Deshpande V, Yoon SS, et al. Endoscopic surveillance of patients with hereditary diffuse gastric cancer: biopsy recommendations after topographic distribution of cancer foci in a series of $10 \mathrm{CDH1}$-mutated gastrectomies. Am J Surg Pathol. 2012;36:1709-17.

104. National Comprehensive Cancer Network Guidelines version 1. 2014. http://www.nccn.org/professionals/physician_gls/pdf/genetics_screening.pdf.

105. Balmana J, Diez O, Rubio IT, Cardoso F. BRCA in breast cancer: ESMO Clinical Practice Guidelines. Ann Oncol. 2011;22 Suppl 6:vi31-34.

106. Sawyer E, Roylance R, Petridis C, Brook MN, Nowinski S, Papouli E, et al. Genetic predisposition to in situ and invasive lobular carcinoma of the breast. PLoS Genet. 2014;10:e1004285. 